\title{
Serotype distribution and incidence of invasive early onset and late onset group B streptococcal disease amongst infants in Singapore
}

Kai-Qian Kam ${ }^{1,2,3,4^{*}}$ D , Koh Cheng Thoon 1,2,3,4 , Wen Sim Nancy Tee ${ }^{5}$, Michelle Lay Teng Ang ${ }^{6}$, Natalie Woon Hui Tan 1,2,3,4, Kee Thai Yeo 2,3,4,7, Jiahui Li ${ }^{1,2,3,4}$ and Chia Yin Chong 1,2,3,4

\begin{abstract}
Background: The current group B streptococcal (GBS) preventive measures had reduced invasive GBS early onset disease (EOD) incidences worldwide, but the late onset disease (LOD) incidences had remained unchanged. Administration of a safe and effective GBS vaccine in addition to the current strategies were thought to be the next steps in reducing the incidences of invasive GBS infection especially LOD. In this study, we aimed to examine the causative GBS serotypes in invasive GBS disease, determine the incidences of EOD and LOD, and compare the risk factors between EOD and LOD.
\end{abstract}

Methods: A retrospective study of infants $\leq 90$-day-old over an 8-year period (2010-2017). The incidences of EOD and LOD were obtained by using patients with EOD and LOD who were born in our institution as the numerator and the live births in our institution per year of the study period as the denominator. Available GBS isolates were serotyped by the National Public Health Laboratory using capsular serotyping methods. The risk factors of EOD and LOD were compared.

Results: A total of 71 infants were identified; 16 (22.5\%) and 55 (77.5\%) of them had EOD and LOD, respectively. Serotype III ( $n=42,71.2 \%$ ) was the most common serotype amongst the 59 isolates available for serotyping. Serotypes la, $\mathrm{Ib}, \mathrm{II}, \mathrm{II}$, and $\mathrm{V}$ accounted for $98.3 \%(\mathrm{n}=58)$ of the invasive $\mathrm{GBS}$ diseases. The overall incidence was 0.42 per 1000 live births. The mean incidences of EOD and LOD were 0.13 per 1000 live births and 0.29 per 1000 live births, respectively. On multivariate analysis, risk factors for LOD as compared to EOD were: Chinese ethnicity (OR 27.1, 95\% Cl 3.0-243.1, $\mathrm{p}=0.003$ ) and negative/unknown maternal GBS status (OR 20.0, 95\% Cl 2.0-250.0, $\mathrm{p}=0.012$ ). Prematurity and intrapartum risk factors (peripartum maternal pyrexia, prolonged rupture of membrane) of EOD were not associated with LOD.

Conclusions: The LOD incidence had remained higher than EOD incidence in our cohort. A GBS vaccine that covers the major causative serotypes found in our cohort can potentially reduce the overall GBS disease burden in the country.

\footnotetext{
*Correspondence: kam.kai.qian@singhealth.com.sg

${ }^{1}$ Infectious Disease Service, Department of Pediatrics, KK Women's

and Children's Hospital, 100 Bukit Timah, Singapore City 229899,

Singapore

Full list of author information is available at the end of the article
}

(C) The Author(s) 2021. Open Access This article is licensed under a Creative Commons Attribution 4.0 International License, which permits use, sharing, adaptation, distribution and reproduction in any medium or format, as long as you give appropriate credit to the original author(s) and the source, provide a link to the Creative Commons licence, and indicate if changes were made. The images or other third party material in this article are included in the article's Creative Commons licence, unless indicated otherwise in a credit line to the material. If material is not included in the article's Creative Commons licence and your intended use is not permitted by statutory regulation or exceeds the permitted use, you will need to obtain permission directly from the copyright holder. To view a copy of this licence, visit http://creativecommons.org/licenses/by/4.0/. The Creative Commons Public Domain Dedication waiver (http://creativeco mmons.org/publicdomain/zero/1.0/) applies to the data made available in this article, unless otherwise stated in a credit line to the data. 
Keywords: GBS, Group B streptococcus, Serotype, Incidence, Risk factors, EOD, LOD, Singapore

\section{Background}

Lancefield group B Streptococcus (GBS) or Streptococcus agalactiae invasive disease continues to cause significant mortality and morbidity in neonates and young infants. In 1996, the Centres for Disease Control and Prevention (CDC) published the consensus guideline on the prevention of perinatal GBS infection and this was subsequently updated in 2019. Based on this guideline, CDC advocated for universal screening of all pregnant women at 35 to 37 weeks of gestation for maternal vaginal and rectal GBS colonization $[1,2]$. It was also recommended that intrapartum antibiotic prophylaxis should be given to the pregnant women who were screened positive for GBS colonization or had other risk factors [1,2]. With the implementation of these guidelines, the incidence of GBS early onset disease (EOD) in the United States of America (USA) had decreased from 1.8 cases per 1000 live births in 1990 to 0.23 cases per 1000 live births in 2015 [3]. Comparatively, the incidence of GBS late onset disease (LOD) had been stable at an average of 0.31 cases per 1000 live births from 2006 to 2015. While the risk factors for GBS EOD are well studied and proven, the risk factors for LOD are less clear although preterm birth had been described to be strongly associated with LOD [2-6].

In 2010, our institution had adopted specific steps to reduce the incidence of invasive GBS disease in our hospital based on recommendations from Royal College of Obstetricians and Gynaecologists (RCOG), CDC and National Institute for Health and Care Excellence (NICE) guidelines $[1,7,8]$. Vaginal GBS screening of pregnant women was conducted at 35 to 37 weeks if there was no planned elective Caesarean section. Indications for intrapartum GBS prophylaxis in the form of intravenous penicillin included any of the following: (i) previous infant with invasive GBS disease (ii) GBS bacteriuria during the current pregnancy (iii) positive GBS screening test during current pregnancy (iv) unknown GBS status and delivery at $<37$ weeks gestation or rupture of membranes $>18 \mathrm{~h}$ or intrapartum temperature $\geq 38.0^{\circ} \mathrm{C}$. For patients where Caesarean section was performed before the labour onset or with intact amniotic membranes, intrapartum GBS prophylaxis was not indicated.

In a previous study done in our institution from 1996 to 1997 where the routine screening for maternal GBS status and administration of intrapartum antibiotics to high-risk pregnant women were not the standard of practice, the GBS EOD and LOD incidences were reported to be 0.265 per 1000 live births and 0.07 per 1000 live births, respectively [9]. There were no further studies that looked at the impact of the implementation of the guidelines on the EOD and LOD incidences after 2010. Data regarding the incidences of GBS EOD and LOD in Singapore and other Asia countries were also limited [10].

With a recent hexavalent capsular polysaccharide conjugate vaccine GBS6 (serotypes Ia, Ib, II, III, IV and V) that was undergoing trials [11], it has been proposed that administration of a safe and effective GBS vaccine in addition to the current GBS prevention strategies may further decrease the incidence of invasive GBS infection especially LOD [12]. We sought to understand the potential serotype coverage of this GBS conjugate vaccine in our population. In this study, we aimed to examine the causative GBS serotypes in invasive GBS disease, determine the incidences of EOD and LOD, and compare the risk factors between EOD and LOD.

\section{Methods}

\section{Setting}

KK Women's and Children's Hospital $(\mathrm{KKH})$ is the largest tertiary pediatric hospital in Singapore with more than 11,000 live births per year with approximately 500 pediatric/neonatal inpatient beds. Our institution also houses $48.5 \%$ of Singapore's neonatal and pediatric admissions with approximately 32,000 pediatric admissions per year (data from Ministry of Health, Singapore). Approval for waiver of consent was obtained from the centralized institution review board of SingHealth Research (Reference number 2017/2031).

\section{Study design}

In this retrospective cohort study, we included infants from birth to day 90 of life who were diagnosed with invasive GBS disease from January 2010 to October 2017 over an 8-year period. A list of patients with GBS isolated from the blood, cerebrospinal fluid (CSF) or other sterile body site cultures was obtained from the KKH microbiology department. Demographic characteristics, the type of invasive GBS disease, perinatal and antenatal risk factors were evaluated from the case notes and electronic medical records.

\section{Laboratory methods}

Before January 2014, bacterial strains from blood and sterile site cultures were isolated on blood agar plates. Bacterial identification was based on Lancefield grouping, microscopic and colony morphology. From January 2014 onwards, isolates were identified using MALDI-TOF mass spectrometry (bioMerieux 
Vitek MS). Quality control for the Vitek MS was performed by using an ATCC control strain (Escherichia coli ATCC 8739) and performed daily as recommended by the manufacturer. Capsular typing was conducted by the National Public Health Laboratory (NPHL) of the Ministry of Health, Singapore. Capsular serotyping involved the use of several sets of multiplex polymerase chain reaction (PCR), each containing primer pairs specific for the various capsular serotypes. Serotype assignment was based on the amplicon size obtained. Each strain was initially subjected to 2 multiplex PCR [13]. PCR primer mix 1 contained primer pairs specific for capsular polysaccharide types Ia, Ib, II, III, and IV and PCR mix 2 contained primer pairs specific for types V, VI, VII or IX, and VIII. The amplicons obtained were visualised by gel electrophoresis. Strains assigned to serotype VII were further subjected to a third multiplex PCR to distinguish between serotype VII and IX [14]. All the GBS isolates except for those from year 2014 were available for capsular typing. Sequence types were determined by using multi-locus sequence typing $[15,16]$. Conventional PCR for the loci of interest was performed. This was followed by Sanger sequencing of the amplicons obtained. Sequences were later compared against the Streptococcus agalactiae multilocus sequence typing (MLST) database to obtain the sequence types.

\section{Study definitions}

GBS EOD and GBS LOD were defined as isolation of GBS from a sterile site from birth to day 6 of life and from day 7 of life to day 90 of life, respectively [2]. GBS bacteremia was defined as growth of GBS from blood culture of the infant. GBS meningitis was defined as growth of GBS from the CSF culture, or a positive CSF latex agglutination test, but negative CSF culture with a positive blood culture for GBS. The incidences of EOD and LOD were obtained by using patients with EOD and LOD who were born in $\mathrm{KKH}$ as the numerator and the live births at $\mathrm{KKH}$ per year of the study period as the denominator.

\section{Statistical analysis}

Statistical analysis was performed using SPSS statistical program version 19 (SPSS, Inc, Chicago, Illinois). Risk factors were compared between EOD and LOD using Chi-square test or Fisher's exact test (when numbers were $<5$ ) for categorical variables. Variables with p values of $<0.2$ on univariate analysis were selected for multivariate analysis via binary logistic regression to identify risk factors that predicted LOD. All statistical tests were twotailed and a p value $<0.05$ was statistically significant.

\section{Results}

\section{Patient's characteristics}

Seventy-one infants with invasive GBS disease were identified; 16 (22.5\%) of them had EOD, 55 (77.5\%) of them had LOD. Thirty-nine infants $(54.9 \%)$ were born in $\mathrm{KKH}$ while the remaining were born in other hospitals. The median age where EOD and LOD had occurred was 1 day-old (interquartile range $[\mathrm{IQR}]=1-3$ ) and 34 dayold (IQR $=17-64)$, respectively. Bacteremia was the predominant invasive disease in $76.1 \%(n=54)$ of the infants (Table 1). There was a larger percentage of infants with LOD who presented with meningitis (with or without concomitant bacteremia) $(\mathrm{n}=14,25.5 \%)$ as compared to EOD $(n=1,6.3 \%)$. None of the infants in our cohort had received outpatient antibiotics for their febrile illness prior to the presentation to the hospital. The infants' mothers did not have any chronic medical conditions and they were not on immunosuppressive therapies prior to delivery. All the mothers tested negative for human immunodeficiency virus (HIV) during the antenatal period. A total of 37 infants' mothers (52.1\%) were screened for GBS during pregnancy; 10 mothers were determined to have GBS infection or colonization, and 27 mothers were screened negative for GBS.

\section{Clinical course and outcome}

All infants survived the GBS invasive disease episode, and no infants were readmitted for recurrence of GBS disease during the study period. In our cohort, GBS bacteremia was treated with an average of 10 to 14 days of intravenous penicillin/ampicillin or ceftriaxone/cefotaxime while GBS meningitis required an average of 21 days of penicillin/ampicillin or ceftriaxone with or without 5 days of gentamicin for synergistic effect. Two neonates with LOD had meningitis with subdural collection and required 6 to 8 weeks of antibiotic treatment. They did not have any surgical intervention. Another neonate with EOD had GBS bacteremia with right hip septic arthritis, left endophthalmitis and urinary tract infection on day 6 of life. He underwent right hip arthrotomy and washout, and left lensectomy. The fluid culture from the right hip and left vitreous fluid were positive for GBS.

Three neonates with EOD and 1 neonate with LOD were admitted to the Intensive Care Unit for septic shock requiring inotropic support and had multi-organ dysfunction. Amongst these four infants, one neonate underwent 5 days of extracorporeal membrane oxygenation (ECMO) for intractable septic shock.

\section{Serotype distribution}

Out of the 71 cases of invasive GBS disease, 59 isolates were sent for serotyping in the NPHL (Fig. 1). Serotype 
Table 1 Clinical presentation and risk factors of infants with invasive GBS Infection in KKH, Singapore (2010-2018)

\begin{tabular}{|c|c|c|c|c|c|c|c|c|}
\hline \multirow[t]{2}{*}{ Patient characteristics } & \multirow{2}{*}{$\begin{array}{l}\operatorname{LOD}^{a} \\
(n=55)\end{array}$} & \multirow{2}{*}{$\begin{array}{l}\text { EOD }^{a} \\
(n=16)\end{array}$} & \multicolumn{3}{|c|}{ Univariate analysis } & \multicolumn{3}{|c|}{ Multivariate analysis $^{b}$} \\
\hline & & & Odds ratio & $95 \% \mathrm{Cl}$ & $p$ value & Odds ratio & $95 \% \mathrm{Cl}$ & $\mathrm{p}$ value \\
\hline Day of life when GBS infection occurred, median (IQR) & $34(17-64)$ & $1(1-3)$ & NA & & & NA & & \\
\hline Type of disease & & & NA & & & NA & & \\
\hline Bacteremia only & $40(72.7)$ & $14(87.5)$ & & & & & & \\
\hline Meningitis only & $2(3.6)$ & 0 & & & & & & \\
\hline Bacteremia and meningitis & $12(21.8)$ & $1(6.3)$ & & & & & & \\
\hline Bacteremia, endophthalmitis and arthritis & 0 & $1(6.3)$ & & & & & & \\
\hline Arthritis & $1(1.8)$ & 0 & & & & & & \\
\hline Mode of delivery ${ }^{c}$ & & & 0.2 & $0.05-1.1$ & 0.058 & - & & 0.138 \\
\hline Normal or assisted vaginal delivery & $33(60.0)$ & $14(87.5)$ & & & & & & \\
\hline Caesarean section & $20(36.4)$ & $2(12.5)$ & & & & & & \\
\hline Race & & & 15.6 & $3.2-76.6$ & $<0.001$ & 27.1 & $3.0-243.1$ & 0.003 \\
\hline Chinese & $38(69.1)$ & $2(12.5)$ & & & & & & \\
\hline Non-Chinese & $17(30.9)$ & $14(87.5)$ & & & & & & \\
\hline Gender & & & 1.0 & $0.3-3.1$ & 0.961 & NA & & \\
\hline Male & $34(61.8)$ & $10(62.5)$ & & & & & & \\
\hline Female & $21(38.2)$ & $6(37.5)$ & & & & & & \\
\hline Gestational age & & & 0.4 & $0.1-1.2$ & 0.081 & - & & 0.480 \\
\hline Preterm ${ }^{d}$ & $12(21.8)$ & $7(43.8)$ & & & & & & \\
\hline Term & $43(78.2)$ & $9(56.3)$ & & & & & & \\
\hline Birth weight & & & 2.7 & $0.8-9.2$ & 0.104 & - & & 0.555 \\
\hline Normal birth weight & $45(81.8)$ & $10(62.5)$ & & & & & & \\
\hline Low birth weight & $10(18.2)$ & $6(37.5)$ & & & & & & \\
\hline Maternal GBS status & & & 10.0 & $2.0-33.3$ & 0.007 & 20.0 & $0.004-0.5$ & 0.012 \\
\hline Negative or unknown & $51(92.7)$ & $10(62.5)$ & & & & & & \\
\hline Infection or colonization & $4(7.3)$ & $6(37.5)$ & & & & & & \\
\hline Adequate intrapartum antibiotics & & & 3.5 & $1.0-12.4$ & 0.042 & - & & 0.637 \\
\hline Yes or not required & $47(85.5)$ & $10(62.5)$ & & & & & & \\
\hline No & $8(14.5)$ & $6(37.5)$ & & & & & & \\
\hline Prolonged rupture of membrane & & & $N A^{f}$ & $N A^{f}$ & 0.267 & NA & & \\
\hline Yes & $4(7.3)$ & $0(0)$ & & & & & & \\
\hline No & $51(92.7)$ & $16(100)$ & & & & & & \\
\hline Peripartum maternal pyrexia & & & 0.2 & $0.03-1.1$ & 0.072 & - & & 0.759 \\
\hline Yes & $2(3.6)$ & $3(18.8)$ & & & & & & \\
\hline No & $53(96.4)$ & $13(81.3)$ & & & & & & \\
\hline Serotypes $^{9}$ & & & 5.3 & $1.5-19.3$ & 0.007 & - & & 0.099 \\
\hline III & $36(65.5)$ & $6(37.5)$ & & & & & & \\
\hline Others & $9(16.4)$ & $8(50.0)$ & & & & & & \\
\hline
\end{tabular}

KKH KK Women's and Children's Hospital, LOD late onset disease, EOD early onset disease, IQR interquartile range, GBS group B streptococcus, NA not applicable

${ }^{a}$ Unless otherwise indicated, data are expressed as number (percentage) of patients

${ }^{\mathrm{b}}$ Multivariate analysis included the following variables: race, mode of delivery, gestational age, birth weight, maternal GBS status, adequate antepartum antibiotics, maternal pyrexia, serotypes. Gender was not included as logistic regression was done for variables on univariate analysis where $p<0.2$

' 2 missing data for LOD

${ }^{d}$ Preterm is defined as gestational age of less than 37 weeks

e Prolonged rupture of membrane is defined as rupture of membrane for more than $18 \mathrm{~h}$ before delivery

${ }^{f}$ Odds ratio is invalid as there were no EOD cases with prolonged rupture of membrane

g 12 missing data; 10 and 2 isolates were not serotyped for LOD and EOD, respectively 

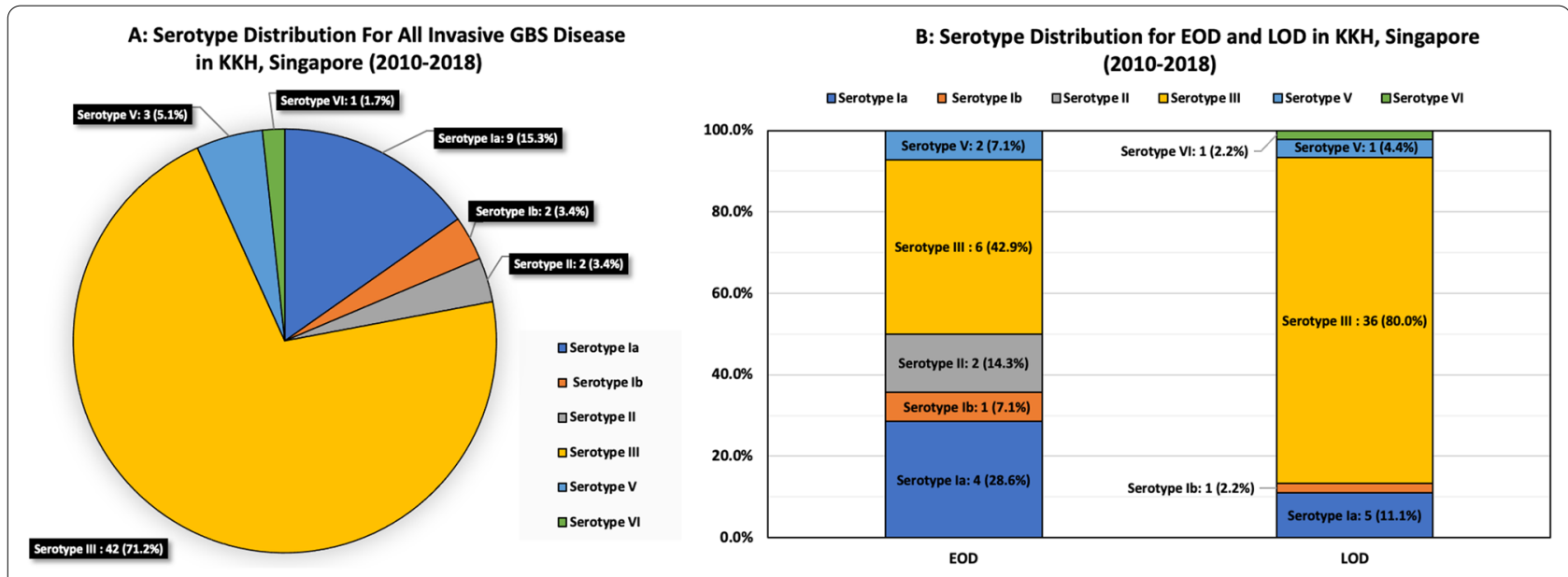

Fig. 1 Overall serotype distribution for GBS disease detected in KKH, Singapore, from 2010 to 2018. This is further classified into EOD versus LOD

Table 2 Serotype distribution leading to bacteraemia and meningitis in KKH, Singapore (2010-2018)

\begin{tabular}{lccl}
\hline $\begin{array}{l}\text { GBS } \\
\text { serotypes }^{\text {a }}\end{array}$ & $\begin{array}{l}\text { Number } \\
(\%) \\
(\mathbf{n}=\mathbf{5 9 )}\end{array}$ & $\begin{array}{l}\text { Bacteremia without } \\
\text { meningitis (\%) } \\
(\mathbf{n}=\mathbf{4 5})\end{array}$ & $\begin{array}{l}\text { Meningitis with or } \\
\text { without bacteremia } \\
(\%)(\mathbf{n}=\mathbf{1 4})\end{array}$ \\
\hline la & $9(15.3)$ & $9(20.0)$ & 0 \\
Ib & $2(3.4)$ & $2(4.4)$ & 0 \\
II & $2(3.4)$ & $2(4.4)$ & 0 \\
III & $42(71.2)$ & $28(62.2)$ & $14(100)$ \\
$\mathrm{V}$ & $3(5.1)$ & $3(6.7)$ & 0 \\
$\mathrm{Vl}$ & $1(1.7)$ & $1(2.2)$ & 0 \\
\hline
\end{tabular}

a 12 missing serotype in 2014

III, mainly in the form of serotype III ST17 or ST1340, was the most common serotype in both the EOD $(n=6$, $37.5 \%)$ and LOD groups $(\mathrm{n}=36,65.5 \%$; total $\mathrm{n}=42$, $71.2 \%)$. Serotype Ia was the second most common serotype identified $(\mathrm{n}=9,15.3 \%)$ followed by serotype $\mathrm{V}$ $(\mathrm{n}=3,5.1 \%)$. Serotypes Ia, Ib, II, III, and V accounted for $98.3 \%(n=58)$ of the serotypes sent for testing while serotypes Ia, Ib and III $(n=53)$ were seen in $89.8 \%$ of the GBS isolates that we had identified. All the cases of meningitis (with or without concomitant bacteremia) were caused by serotype III (Table 2). All the GBS isolates were susceptible to penicillin.

\section{Incidence of EOD and LOD}

The mean incidence of invasive GBS disease was 0.42 per 1000 live births (range: 0.08 to 0.59 per 1000 live births) (Table 3). The mean incidences of EOD and LOD were 0.13 per 1000 live births (range: 0 to 0.18 per 1000 live births) and 0.29 per 1000 live births (range: 0.08 to 0.51 per 1000 live births), respectively. The LOD incidence was at a mean of 2 times (range: 1.0 to 6.0 ) of EOD incidence per year. The number of LOD cases was consistently higher than EOD cases in each year of the study.

\section{Risk factors of invasive GBS LOD}

As compared to EOD, GBS LOD was associated with the Chinese ethnicity $(69.1 \%$ in LOD vs $12.5 \%$ in EOD, OR 15.6, 95\% CI 3.2-76.6, $\mathrm{p}<0.001)$, negative/unknown maternal GBS status $(92.7 \%$ in LOD vs $62.5 \%$ in EOD, OR 10.0, 95\% CI 2.0-33.3, $\mathrm{p}=0.007)$ and serotype III (65.5\% in LOD vs $37.5 \%$ in EOD, OR 5.3, 95\% CI $1.5-$ 19.3, $\mathrm{p}=0.007$ ) (Table 1) in the univariate analysis. On multivariate analysis, both Chinese ethnicity and negative/unknown maternal GBS status were still found to be significantly associated with GBS LOD. Risk factors associated with LOD were: Chinese ethnicity (OR 27.1, 95\% CI 3.0-243.1, $\mathrm{p}=0.003$ ) and negative/unknown maternal GBS status (OR 20.0, 95\% CI 2.0-250.0, $\mathrm{p}=0.012$ ). Prematurity and intrapartum risk factors (peripartum maternal pyrexia and prolonged rupture of membrane) of EOD were not associated with LOD (Table 1).

\section{Discussion}

This is the first study that showed the invasive GBS disease serotype distribution in Singapore. Serotype III was the most common serotype in both the EOD and LOD groups. Serotypes Ia, Ib, II, III, and V also accounted for 98.3\% $(n=58)$ of the serotypes detected for invasive GBS diseases. We also showed that the mean incidence of invasive GBS disease was 0.42 per 1000 live births. The LOD incidence was at a mean of 2 times (range: 1.0 to 6.0) of EOD incidence per year despite the GBS preventive strategies. Known risk factors of EOD such as prematurity, peripartum maternal pyrexia and prolonged 
Table 3 Incidence of EOD and LOD in KK Women's and Children's Hospital, Singapore (2010-2018)

\begin{tabular}{|c|c|c|c|c|c|c|c|}
\hline \multirow[t]{2}{*}{ Year } & \multirow[t]{2}{*}{$\begin{array}{l}\text { Number of live } \\
\text { births in KKH }\end{array}$} & \multirow[t]{2}{*}{$\begin{array}{l}\text { Number of } \\
\text { EOD }\end{array}$} & \multirow[t]{2}{*}{$\begin{array}{l}\text { Number of } \\
\text { LOD }\end{array}$} & $\begin{array}{l}\text { Incidence of } \\
\text { EOD }\end{array}$ & $\begin{array}{l}\text { Incidence of } \\
\text { LOD }\end{array}$ & $\begin{array}{l}\text { Total incidence of EOD } \\
\text { and LOD }\end{array}$ & \multirow[t]{2}{*}{ LOD/EOD } \\
\hline & & & & \multicolumn{3}{|c|}{ Per 1000 live births } & \\
\hline 2010 & 11,271 & 2 & 4 & 0.18 & 0.35 & 0.53 & 2.0 \\
\hline 2011 & 11,776 & 1 & 1 & 0.08 & 0.08 & 0.17 & 1.0 \\
\hline 2012 & 11,794 & 1 & 6 & 0.08 & 0.51 & 0.59 & 6.0 \\
\hline 2013 & 11,055 & 2 & 4 & 0.18 & 0.36 & 0.54 & 2.0 \\
\hline 2014 & 11,782 & 2 & 3 & 0.17 & 0.25 & 0.42 & 1.5 \\
\hline 2015 & 12,061 & 0 & 1 & 0.00 & 0.08 & 0.08 & $N A^{a}$ \\
\hline 2016 & 11,894 & 2 & 3 & 0.17 & 0.25 & 0.42 & 1.5 \\
\hline 2017 & 11,882 & 2 & 5 & $0.17^{b}$ & $0.42^{b}$ & $0.59^{b}$ & $2.5^{\mathrm{b}}$ \\
\hline Mean & NA & NA & NA & 0.13 & 0.29 & 0.42 & 2.0 \\
\hline
\end{tabular}

LOD late onset disease, EOD early onset disease, $N A$ not applicable

${ }^{\text {a }}$ No number as there were 0 EOD cases in 2015

${ }^{\mathrm{b}}$ Incidence of EOD and LOD in 2017 is an underestimate as infants diagnosed with invasive GBS disease beyond October 2017 were not included in this study

rupture of membrane were not associated with LOD. Chinese ethnicity and negative/unknown maternal GBS status were found to be associated with LOD as compared to EOD.

Worldwide, meta-analysis of serotype prevalence showed that GBS serotype III was the predominant serotype $[10,17,18]$. Around $50 \%$ of the EOD and $75 \%$ of the LOD cases were caused by serotype III. Five serotypes (Ia, Ib, II, III and V) were responsible for $97 \%$ of invasive GBS diseases around the world. Our findings mirrored this where serotype III was the most common isolate in our cohort and the serotypes Ia, Ib, II, III, and $\mathrm{V}$ accounted for $98.3 \%$ of the detected GBS isolates in our cohort. Serotypes Ia, Ib and III were also frequently reported to cause invasive GBS disease around the world, and these three serotypes were seen in $89.8 \%$ of the GBS isolates that we had identified. A trivalent (serotype Ia, Ib and III) GBS conjugate vaccine or a hexavalent capsular polysaccharide conjugate vaccine GBS6 (serotypes Ia, Ib, II, III, IV and V) is likely to cover the majority of causative GBS serotypes in our population.

As compared to other Asian countries, our findings were similar to studies from China $[19,20]$ and Taiwan [21] where serotype III was the most common serotype accounting for invasive GBS disease although in Taiwan, serotype VI was the leading cause of EOD from 2007 to 2010. It appears that serotypes leading to invasive GBS disease in infants can be similar although some variations can occur in different geographical locations, climate, and year of study. In our cohort, we also detected 1 EOD which was caused by serotype VI. This serotype does not lead to invasive disease commonly, although it had been reported to lead to significant proportions of maternal GBS colonization in Southeastern
Asia countries previously [10]. We do not have the serotype data of maternal GBS colonization in our cohort to make this comparison.

The mean incidence of invasive GBS disease in our study was 0.42 per 1000 live births which was lower than the reported worldwide pooled incidence of 0.49 per 1000 live births in a systematic review [10]. In studies done in Asia, the overall incidence of GBS disease was 0.31 per 1000 live births and 1.1 per 1000 live births in China and Taiwan, respectively $[19,21]$. Our mean EOD incidence of 0.13 per 1000 live births was also lower than the reported worldwide pooled EOD incidence of 0.41 per 1000 live births. There was a decrease in the incidence of EOD found in this study as compared to the previous finding of 0.265 per 1000 live births before the implementation of steps to reduce invasive GBS disease in our institution [9]. This shows that the burden of GBS EOD in our country had decreased over the years. However, the implementation of the current GBS preventive strategies did not have any impact on the LOD burden. Our mean LOD incidence remained high at 0.29 per 1000 live births. Similar to our findings, other studies also showed that the LOD rates were not affected by the widespread use of intrapartum antibiotic prophylaxis for high-risk pregnant women [1-3, 12, 22]. Twenty-five percent of our infants with LOD had GBS meningitis implying significant morbidity for this group of patients. In a systematic review, $32 \%$ of GBS meningitis survivors had neurodevelopmental impairment at 18 months of followup, including $18 \%$ with moderate to severe neurodevelopmental impairment [23]. New interventions such as GBS vaccine are required to tackle the GBS LOD burden in our country and worldwide. 
The risk factors for EOD had been well described in many studies [2, 22, 24-29]. Prematurity, increased duration of rupture of membranes, maternal intrapartum fever, maternal vaginal GBS colonization and maternal GBS bacteriuria are proven risk factors of GBS EOD. However, the risk factors for LOD are less known. Maternal vaginal GBS colonization was reported to be a risk factor for LOD in a few studies, but these findings were inconsistent $[5,6]$. On the other hand, prematurity was reported to be strongly associated with GBS LOD $[3-6,22]$. In our cohort, only the Chinese ethnicity and negative/unknown antenatal maternal GBS status were associated with LOD after multivariate analysis. This association between LOD and Chinese ethnicity was not previously reported, although the African American ethnicity was associated with GBS LOD in some studies in the United States $[5,22,30]$. This association was thought to be due to socio-economic factors and access to medical care. The association between Chinese ethnicity and LOD in our study may reflect differences in cultural practices and should warrant further investigation. We do not have the socio-economic status of the infants in our population to evaluate the impact of socio-economic factors on GBS LOD.

We also found that LOD was associated with negative/unknown antenatal maternal GBS status, and this suggests that antenatal maternal GBS status is not helpful in estimating the risk of LOD. In settings where elective Caesarean section has been arranged, vaginal GBS screening swabs will not be performed by most Obstetricians since GBS antibiotics prophylaxis will not be recommended for the clinical setting. It is known that vaginal screening swabs may yield false negative result due to the transient GBS colonization in the vaginal tract [11]. Improper sampling can also lead to false negative results as rectovaginal swab for GBS gives the best yield as compared to vaginal swabs [31]. GBS screening is recommended to be done between 35 and 37 weeks of gestation in most guidelines and GBS colonization may still occur after the initial screening tests yield negative result. Moreover, there are other potential sources of GBS transmission from the mother to baby such as contaminated breastmilk with GBS that had been reported to be associated with GBS LOD [32]. It was suggested that the breastmilk might be contaminated through the transmission of GBS from the breastfed infants who had been initially colonized with GBS during delivery or after birth, leading to multiplication of GBS in the mammary ducts and persistent exposure of the infant and mother to GBS thereafter [33, 34]. The other proposed mechanism was the translocation of GBS from the gastrointestinal tract via the lymphatics to the mammary glands [32]. High bacterial load in cases of mastitis and prematurity with less developed immune function were two other factors associated with GBS LOD after the exposure to GBS contaminated breastmilk $[5,35]$. At this point, it is not proven that GBS in breastmilk is indeed the causative factor for LOD and there is not enough evidence for breastfeeding to be discontinued if the breastmilk is found to be GBS positive. There is also no consensus regarding the routine testing of breastmilk for GBS. As our study is a retrospective analysis, we do not have the data to study these potential risk factors of GBS LOD.

Another reported risk factor for LOD was HIV exposure during the antenatal period [36, 37]. None of our infants were born to HIV positive mothers. Lastly, young maternal age and maternal consumption of capsules containing dehydrated placenta were reported to be associated with LOD in the United States in some studies [4, $21,30,38]$. However, no mothers in our study reported consumption of these capsules and we do not have the maternal ages of our cohort to make this comparison.

Our study has some limitations. A small number of GBS isolates were obtained in the 8 years of the study and the isolates in the year 2014 were not available for serotyping. However, based on the fact that the distribution of serotypes in other years of the study had remained largely similar, it is likely that the serotype distribution in 2014 will reflect the trend found in other years. This is a single-centre study although our institution is the biggest tertiary neonatal and paediatric hospital. Based on our calculations, the reported EOD and LOD incidences are estimates for the entire country during the years of study. In our cohort, all of our infants survived the invasive GBS disease and those who recovered with no outstanding concerns were not given long-term follow up. Hence, we do not have long-term developmental follow up data on these infants who were infected with GBS. Based on an earlier study conducted in our institution from Jan 1998 to May 2013, 3 out of 20 (15\%) of the GBS meningitis survivors developed moderate to severe neurodevelopmental impairment [39].

\section{Conclusion}

Serotypes Ia, Ib, II, III, and V account for $98.3 \%(\mathrm{n}=58)$ of the invasive GBS diseases. The overall incidence of invasive GBS disease was 0.42 per 1000 live births, and the LOD incidence was at a mean of 2 times (range: 1.0 to 6.0 ) of EOD incidence per year. A GBS vaccine that covers the major causative serotypes found in our cohort can potentially reduce the overall GBS disease burden in the country. 


\begin{abstract}
Abbreviations
GBS: Group B streptococcus; EOD: Early onset disease; LOD: Late onset disease; IQR: Interquartile range; n: Number; OR: Odds ratio; Cl: Confidence interval: CDC: Centres for Disease Control and Prevention; USA: United States of America; RCOG: Royal College of Obstetricians and Gynaecologists; NICE: National Institute for Health and Care Excellence; KKH: KK Women's and Children's Hospital; CSF: Cerebrospinal fluid; NPHL: National Public Health Laboratory; PCR: Polymerase chain reaction; MLST: Multi-locus sequence typing; HIV: Human immunodeficiency virus; ECMO: Extracorporeal membrane oxygenation.
\end{abstract}

\section{Acknowledgements}

We thank Associate Professor Raymond Lin and Dr. Cui Lin from the National Public Health Laboratory, National Centre of Infectious Diseases, Singapore, for assisting with the serotyping of the GBS isolates.

\section{Authors' contributions}

KQK contributed to the data interpretation, data analysis and writing/revision of the manuscript. CYC contributed to the study design, data interpretation, data analysis and critical revision of the manuscript. KCT contributed to data interpretation and critical revision of the manuscript. WSNT and MLTA contributed to data collection, data interpretation and revision of the manuscript. NWHT, KTY and JL contributed to the critical revision of the manuscript. All authors read and approved the final manuscript.

\section{Funding}

No funding was provided for this research.

\section{Availability of data and materials}

The datasets used and/or analyzed during the current study are available from the corresponding author on reasonable request.

\section{Declarations}

Ethics approval and consent to participate

The need for ethics approval and consent to participate were waived by the centralized institution review board of SingHealth Research (Reference number 2017/2031).

\section{Consent for publication}

Not applicable.

\section{Competing interests}

The authors declare that they have no competing interests.

\section{Author details}

'Infectious Disease Service, Department of Pediatrics, KK Women's and Children's Hospital, 100 Bukit Timah, Singapore City 229899, Singapore. ${ }^{2}$ Yong Loo Lin School of Medicine, National University of Singapore, Singapore City, Singapore. ${ }^{3}$ Duke-National University of Singapore Medical School, Singapore City, Singapore. ${ }^{4}$ Lee Kong Chian School of Medicine, Nanyang Technological University, Singapore City, Singapore. ${ }^{5}$ Department of Laboratory Medicine, National University Health System, Singapore City, Singapore. ${ }^{6}$ National Public Health Laboratory, National Centre of Infectious Diseases, Singapore City, Singapore. ${ }^{7}$ Department of Neonatology, KK Women's and Children's Hospital, Singapore City, Singapore.

Received: 5 February 2020 Accepted: 22 November 2021

Published online: 07 December 2021

\section{References}

1. Verani JR, McGee L, Schrag SJ. Prevention of perinatal group B streptococcal disease-revised guidelines from CDC, 2010. MMWR Recomm Rep. 2010;59(RR-10):1-36.

2. Puopolo KM, Lynfield R, Cummings JJ, COMMITTEE ON FETUS AND NEWBORN, COMMITTEE ON INFECTIOUS DISEASES. Management of infants at risk for Group B Streptococcal disease [published correction appears in Pediatrics. 2019 Oct;144(4):]. Pediatrics. 2019;144(2):e20191881
3. Nanduri SA, Petit S, Smelser C, Apostol M, Alden NB, Harrison LH, et al. Epidemiology of invasive early-onset and late-onset Group B Streptococcal disease in the United States, 2006 to 2015: multistate laboratory and population-based urveillance. JAMA Pediatr. 2019;173(3):224-33.

4. Pintye J, Saltzman B, Wolf E, Crowell CS. Risk factors for late-onset group B streptococcal disease before and after implementation of universal screening and intrapartum antibiotic prophylaxis. J Pediatr Infect Dis Soc 2016;5(4):431-8.

5. Berardi A, Rossi C, Lugli L, Creti R, Bacchi Reggiani ML, Lanari M, et al. Group B streptococcus late-onset disease: 2003-2010. Pediatrics. 2013;131(2):e361-8.

6. Bartlett AW, Smith B, George CR, McMullan B, Kesson A, Lahra MM, et al. Epidemiology of late and very late onset group B streptococcal disease: fifteen-year experience from two Australian tertiary pediatric facilities. Pediatr Infect Dis J. 2017;36(1):20-4.

7. Royal College of Obstetricians \& Gynaecologists. Group B streptococcal disease, early-onset (green-top guideline no. 36). https://www.rcog. org.uk/en/guidelines-research-services/guidelines/gtg36/. Accessed 5 Aug 2021.

8. National Institute for Health and Care Excellence. Neonatal infection: antibiotics for prevention and treatment. 2021. https://www.nice.org uk/guidance/ng195. Accessed 5 Aug 2021.

9. Tan KW, Tay L, Lin R, Daniel M, Bhavani S, Lim SH. Group B Streptococcal septicaemia/meningitis in neonates in a Singapore teaching hospital. Aust N Z J Obstet Gynaecol. 1998;38(4):418-23.

10. Seale AC, Blencowe H, Bianchi-Jassir F, Embleton N, Bassat $Q$, Ordi J, et al. Stillbirth with group B streptococcus disease worldwide: systematic review and meta-analyses. Clin Infect Dis. 2017;65(suppl_2):S125-32.

11. Buurman ET, Timofeyeva Y, Gu J, Kim JH, Kodali S, Liu Y, et al. A novel hexavalent capsular polysaccharide conjugate vaccine (GBS6) for the prevention of neonatal group B streptococcal infections by maternal immunization. J Infect Dis. 2019;220(1):105-15.

12. Schrag SJ, Verani JR. Intrapartum antibiotic prophylaxis for the prevention of perinatal group B streptococcal disease: experience in the United States and implications for a potential group B streptococcal vaccine. Vaccine. 2013;31(Suppl 4):D20-6.

13. Poyart C, Tazi A, Réglier-Poupet H, Billoët A, Tavares N, Raymond J, et al. Multiplex PCR assay for rapid and accurate capsular typing of group $B$ streptococci. J Clin Microbiol. 2007;45(6):1985-8.

14. Imperi M, Pataracchia M, Alfarone G, Baldassarri L, Orefici G, Creti R. A multiplex PCR assay for the direct identification of the capsular type (la to IX) of Streptococcus agalactiae. J Microbiol Methods. 2010;80(2):212-4.

15. Public databases for molecular typing and microbial genome diversity. Streptococcus agalactiae (group B streptococcus, GBS). https://pubmlst. org/organisms/streptococcus-agalactiae/. Accessed 7 Sept 2021.

16. Jones N, Bohnsack JF, Takahashi S, Oliver KA, Chan MS, Kunst F, et al. Multilocus sequence typing system for group B streptococcus. J Clin Microbiol. 2003;41(6):2530-6.

17. Madrid L, Seale AC, Kohli-Lynch M, Edmond KM, Lawn JE, Heath PT, et al. Infant group B streptococcal disease incidence and serotypes worldwide: systematic review and meta-analyses. Clin Infect Dis. 2017;65(suppl_2):S160-72.

18. Edmond KM, Kortsalioudaki C, Scott S, Schrag SJ, Zaidi AK, Cousens S, et al. Group B streptococcal disease in infants aged younger than 3 months: systematic review and meta-analysis. Lancet. 2012;379(9815):547-56.

19. Ji W, Liu H, Madhi SA, Cunnington M, Zhang Z, Dangor Z, et al. Clinical and molecular epidemiology of invasive group B streptococcus disease among infants, China. Emerg Infect Dis. 2019;25(11):2021-30.

20. Zhu Y, Wu J, Zheng X, Liu D, Xu L, Chen D, et al. Etiological serotype and genotype distributions and clinical characteristics of group B streptococcus-inducing invasive disease among infants in South China. BMC Pediatr 2020;20(1):146.

21. Lin HC, Chen CJ, Chiang KH, Yen TY, Ho CM, Hwang KP, et al. Clonal dissemination of invasive and colonizing clonal complex 1 of serotype VI group B Streptococcus in central Taiwan. J Microbiol Immunol Infect. 2016;49(6):902-9.

22. Jordan HT, Farley MM, Craig A, Mohle-Boetani J, Harrison LH, Petit S, et al. Revisiting the need for vaccine prevention of late-onset neonatal group 
B streptococcal disease: a multistate, population-based analysis. Pediatr Infect Dis J. 2008;27(12):1057-64.

23. Kohli-Lynch M, Russell NJ, Seale AC, Dangor Z, Tann CJ, Baker CJ, et al. Neurodevelopmental impairment in children after group B streptococcal disease worldwide: systematic review and meta-analyses. Clin Infect Dis. 2017;65(suppl_2):S190-9.

24. Goldenberg RL, Hauth JC, Andrews WW. Intrauterine infection and preterm delivery. N Engl J Med. 2000;342(20):1500-7.

25. Van Dyke MK, Phares CR, Lynfield R, Thomas AR, Arnold KE, Craig AS, et al. Evaluation of universal antenatal screening for group B streptococcus. N Engl J Med. 2009;360(25):2626-36.

26. Mukhopadhyay S, Dukhovny D, Mao W, Eichenwald EC, Puopolo KM. 2010 perinatal GBS prevention guideline and resource utilization. Pediatrics. 2014;133(2):196-203.

27. Benitz WE, Gould JB, Druzin ML. Risk factors for early-onset group B streptococcal sepsis: estimation of odds ratios by critical literature review. Pediatrics. 1999;103(6):e77.

28. Schuchat A, Deaver-Robinson K, Plikaytis BD, Zangwill KM, Mohle-Boetani J, Wenger JD. Multistate case-control study of maternal risk factors for neonatal group B streptococcal disease. The active surveillance study group. Pediatr Infect Dis J. 1994;13(7):623-9.

29. Schuchat A, Zywicki SS, Dinsmoor MJ, Mercer B, Romaguera J, O'Sullivan $\mathrm{MJ}$, et al. Risk factors and opportunities for prevention of early-onset neonatal sepsis: a multicenter case-control study. Pediatrics. 2000;105(1 Pt 1):21-6.

30. Weston EJ, Pondo T, Lewis MM, Martell-Cleary P, Morin C, Jewell B, et al. The burden of invasive early-onset neonatal sepsis in the United States, 2005-2008. Pediatr Infect Dis J. 2011;30(11):937-41.

31. El Aila NA, Tency I, Claeys G, Saerens B, Cools P, Verstraelen H, et al. Comparison of different sampling techniques and of different culture methods for detection of group B streptococcus carriage in pregnant women. BMC Infect Dis. 2010;10:285.

32. Zimmermann $\mathrm{P}$, Gwee $\mathrm{A}$, Curtis $\mathrm{N}$. The controversial role of breast milk in GBS late-onset disease. J Infect. 2017;74(Suppl 1):S34-40.

33. Byrne PA, Miller C, Justus K. Neonatal group B streptococcal infection related to breast milk. Breastfeed Med. 2006; 1(4):263-70.

34. Bertini G, Dani C. Group B streptococcal late-onset sepsis with submandibular phlegmon in a premature infant after beginning of breast-feeding. J Matern Fetal Neonatal Med. 2008;21:213-5.

35. Panczuk JK, Unger S, Francis J, Bando N, Kiss A, O'Connor DL. Introduction of bovine-based nutrient fortifier and gastrointestinal inflammation in very low birth weight infants as measured by fecal calprotectin. Breastfeed Med. 2016;11(1):2-5.

36. Cutland CL, Schrag SJ, Thigpen MC, Velaphi SC, Wadula J, Adrian PV, et al. Increased risk for group B Streptococcus sepsis in young infants exposed to HIV, Soweto, South Africa, 2004-2008(1). Emerg Infect Dis. 2015;21(4):638-45.

37. Epalza C, Goetghebuer T, Hainaut M, Prayez F, Barlow P, Dediste A, et al. High incidence of invasive group B streptococcal infections in HIVexposed uninfected infants. Pediatrics. 2010;126(3):e631-8.

38. Buser GL, Mató S, Zhang AY, Metcalf BJ, Beall B, Thomas AR. Notes from the field: late-onset infant group $b$ streptococcus infection associated with maternal consumption of capsules containing dehydrated placenta - Oregon, 2016. MMWR Morb Mortal Wkly Rep. 2017;66(25):677-8.

39. Wee LY, Tanugroho RR, Thoon KC, Chong CY, Choong CT, Krishnamoorthy $\mathrm{S}$, et al. A 15-year retrospective analysis of prognostic factors in childhood bacterial meningitis. Acta Paediatr. 2016;105(1):e22-9.

\section{Publisher's Note}

Springer Nature remains neutral with regard to jurisdictional claims in published maps and institutional affiliations.
Ready to submit your research? Choose BMC and benefit from:

- fast, convenient online submission

- thorough peer review by experienced researchers in your field

- rapid publication on acceptance

- support for research data, including large and complex data types

- gold Open Access which fosters wider collaboration and increased citations

- maximum visibility for your research: over $100 \mathrm{M}$ website views per year

At $\mathrm{BMC}$, research is always in progress.

Learn more biomedcentral.com/submissions 